\title{
Erratum to: Human splanchnic amino-acid metabolism
}

\author{
Evelien P. J. G. Neis ${ }^{1,2}$ - S. Sabrkhany ${ }^{3,5}$ - I. Hundscheid ${ }^{2}$ - D. Schellekens ${ }^{2}$ \\ K. Lenaerts ${ }^{1,2}$ - S. W. Olde Damink ${ }^{2}$ E. E. Blaak ${ }^{1,3}$ - C. H. C. Dejong ${ }^{1,2,4}$. \\ Sander S. Rensen ${ }^{2}$ (])
}

Published online: 7 April 2017

(C) Springer-Verlag Wien 2017

\section{Erratum to: Amino Acids (2017) 49:161-172 \\ DOI 10.1007/s00726-016-2344-7}

In the subsection "Arterial venous differences" of the "Materials and methods" section, the below formula was wrongly published. The correct version is given below.

$\Delta \mathrm{AV}$ liver $=[0.3 \times A+0.7 \times \mathrm{PV}]-[\mathrm{HV}]$.

The online version of the original article can be found under doi:10.1007/s00726-016-2344-7.

Sander S. Rensen

s.rensen@maastrichtuniversity.nl

1 Top Institute Food and Nutrition, P.O. Box 557, 6700

AN Wageningen, The Netherlands

2 Department of General Surgery, NUTRIM School for Nutrition and Translational Research in Metabolism, Maastricht University, Universiteitssingel 50, 6229 ER Maastricht, The Netherlands

3 CARIM School for Cardiovascular Diseases, Maastricht University Medical Centre, P.O. Box 5800, 6229 HX Maastricht, The Netherlands

4 Department of Human Biology, NUTRIM School for Nutrition and Translational Research in Metabolism, Maastricht University, 6229 ER Maastricht, The Netherlands

5 GROW School for Oncology and Developmental Biology, Maastricht University, P.O. Box 616, 6200 MD Maastricht, The Netherlands 